\title{
Daily costs of prostaglandin analogues as monotherapy or in fixed combinations with timolol, in Denmark, Finland, Germany and Sweden
}

This article was published in the following Dove Press journal:

Clinical Ophthalmology

14 August 2009

Number of times this article has been viewed

\author{
Anders Bergström' \\ Frédérique Maurel $^{2}$ \\ Claude Le Pen ${ }^{3}$ \\ Emilie Lamure ${ }^{2}$ \\ Michael Kent ${ }^{4}$ \\ Isabelle Bardoulat ${ }^{2}$ \\ Gilles Berdeaux ${ }^{5,6}$ \\ 'Lund Hospital, Lund, Sweden; \\ IIMS France, Puteaux, France; \\ ${ }^{3}$ Université Paris-Dauphine, \\ Paris, France; ${ }^{4}$ Alcon Inc, Fort \\ Worth, Texas, USA; ${ }^{5}$ Alcon France \\ SA, Rueil-Malmaison, France; \\ ${ }^{6}$ Conservatoire National des Arts et \\ Métiers, Paris, France
}

Background: To compare the daily costs of 3 prostaglandin analogues (bimatoprost, latanoprost, travoprost), alone, and associated with timolol in 4 European countries (Denmark, Finland, Germany, and Sweden).

Methods: Six glaucoma products were sampled by buying 5 bottles from 1 suburban pharmacy in each of the 4 countries. Drops were weighed by a single operator at 1 site according to standardized procedures. Residual drops were then counted. Unit bottle costs were estimated from tariff lists. Eye-drop weights were entered into a nested analysis of variance comprising drug, instillation day, country, the interaction, and a sample factor nested within the country factor. Effectiveness was represented by treatment failure rates estimated from a meta-analysis and a general practitioner survey.

Results: Every drug bottle contained sufficient drops to treat 1 patient for 28/31 days. Drop-size heterogeneity between countries was observed for bimatoprost and bimatoprost/timolol. Mean travoprost and travoprost/timolol drop-sizes were the smallest, and drop-counts per bottle were the lowest for latanoprost, or latanoprost/timolol. In all 4 countries annual costs were least for travoprost and travoprost/timolol.

Conclusions: On taking into account drug costs and effectiveness, travoprost and travoprost/ timolol were cheaper and more effective than latanoprost and latanoprost/timolol and were cheaper than bimatoprost and bimatoprost/timolol.

Keywords: prostaglandin analogue, economics, daily cost

\section{Introduction}

Glaucoma prevalence in industrialized countries ranges from $1 \%$ to $3 \%$ and constitutes a major cause of irreversible blindness worldwide. ${ }^{1}$ Its most common form in adults is primary open-angle glaucoma (POAG), which is associated with increased intraocular pressure (IOP) and leads to progressive visual field loss. ${ }^{2}$ To preserve visual function, it is essential to prevent optic nerve damage by decreasing intraocular hypertension.

First-line treatment in POAG aims at reducing IOP, usually with one of the following three prostaglandin analogues (PGAs): latanoprost $0.005 \%$ (Xalatan ${ }^{\circledR}$; Pfizer Inc., New York, NY, USA), travoprost 0.004\% (Travatan ${ }^{\circledR}$; Alcon Inc., Fort Worth, Texas, USA), and bimatoprost $0.03 \%$ (Lumigan ${ }^{\circledR}$; Allergan Inc., Irvine, CA, USA). When any of these single agents fails to control IOP sufficiently it is customary to add a beta-blocker, often in a fixed combination. Various fixed combinations have recently become available, eg, bimatoprost $0.03 \%$ /timolol (Ganfort ${ }^{\circledR}$; Allergan Inc., Irvine, CA, USA), latanoprost $0.005 \% /$ timolol (Xalacom ${ }^{\circledR}$; Pfizer Inc, New York, NY, USA), and travoprost 0.004\%/timolol (DuoTrav ${ }^{\circledR}$; Alcon Inc., Fort Worth, Texas, USA).
Correspondence: Gilles Berdeaux 4, rue Henri Sainte-Claire Deville, F-92563 Rueil-Malmaison, France

Tel +33 | 47 I0 4860

Fax +33 I 47 I0 2770

Email gillesberdeaux@alconlabs.com 
Optimization of expenditure on medical resources first depends on evaluating efficacy and safety data, but subsequently extends to disease costs and, in particular, treatment costs. Several clinical trials have directly compared the aforementioned PGAs, in monotherapy and in fixed combinations with timolol. ${ }^{3-18}$ A meta-analysis by Denis et a ${ }^{19}$ found that IOP was better controlled ( $1 \mathrm{mmHg}$, approx) by travoprost or bimatoprost than by latanoprost, ie, the incidence rate ratio (IRR) of IOPs $>18 \mathrm{mmHg}$ was 1.17 $(1.00 ; 1.35)$ higher with latanoprost.

Treatment costs are important not only to health authorities but also to general practitioners responsible for their drug budgets, as in Germany. Several studies have focussed on glaucoma drug costs, using various methods and economic indicators (eg, costs per mmHg decrease; costs to attain a 20\% IOP decrease). ${ }^{20-24}$ The number of eye-drops in a bottle (drop-count) is also a major item when estimating daily treatment costs, as the drop-count fixes the number of treatment days delivered per bottle.

According to the study conducted by Frankel in the United States, bimatoprost $0.03 \%$ had the lowest monthly and annual costs and the greatest cost effectiveness for lowering IOP compared with latanoprost $0.005 \%$ and travoprost $0.004 \%$. The savings came from more drops in a bimatoprost bottle (113 for bimatoprost $0.03 \%, 84$ for latanoprost $0.005 \%$, and 83 for travoprost $0.004 \%$ ), resulting in longer treatment duration per bottle. Cost effectiveness was based on an average cost per mmHg reduction IOP.

The aim of this manuscript was to check whether the above results would apply to 4 selected EU countries. This study compares the daily and annual treatment costs associated with various first-line and second-line treatments for patients with glaucoma or IOP in several European countries.

\section{Methods}

The study included 4 European countries: Denmark, Finland, Germany, and Sweden. Three first-line, single agents for IOP control were compared, ie, bimatoprost $0.03 \%$ (BP), latanoprost $0.005 \%$ (LP), and travoprost $0.004 \%$ (TP). Similarly, 3 fixed-combination agents for second-line therapy were compared, ie, bimatoprost $0.03 \% /$ timolol (BP/T), latanoprost $0.005 \% /$ timolol (LP/T), and travoprost $0.004 \% /$ timolol (TP/T).

\section{Drop-count estimate}

Each of the 6 glaucoma treatments was sampled by buying 5 new eye-drop bottles ( 4 bottles of travoprost $0.004 \%$ in Finland, only) from 1 suburban pharmacist in each of the 4 countries. All bottles had similar expiry dates and all were sent to the US for centralized drop-count and drop-size evaluations, performed by a single assessor in order to reduce measurement variability.

Measurement methods followed standard operating procedures. Bottles were numbered sequentially and all outer encumbrances were removed (eg, shrink bands and obvious closure rings). Each container was weighed and its dispensing angle for drop expression was specified and recorded. A weigh boat, or suitable container, was centered on the balance pan and tared. A sample bottle was selected and shaken, as appropriate, before removing the cap. Any overflow was recorded before the bottle was held above the weigh boat, at the desired angle from horizontal, and finally 1 drop was dispensed into the weigh boat. The bottle number and drop weight ('drop-size' to the nearest $0.0001 \mathrm{~g}, 0.1 \mathrm{mg}$ ) were recorded. The sequence was repeated for the second drop. The cap was then replaced and the bottle stored upright for reweighing on subsequent days.

According to the relevant Summaries of Product Characteristics, ${ }^{25}$ shelf-life after bottle opening ranged from 28 to 31 days, depending on the product and country. Hence a maximum of 62 measurements were performed, as above, on every bottle of all 6 drugs purchased in each of the 4 countries, to represent patients' daily instillations. On the day when the last of 62 weighings was completed, the procedure continued until the bottle was empty in order to measure the total fill of each bottle and, in due course, estimate the average number of drops in a bottle and total fill (sum of drop weights). The percentage of total product remaining in each bottle, after 62 weighings were completed, was also estimated and averaged. Observations were averaged for the total fill in grams (SD; range), drop-size in milligrams (SD; range), and total drop-count per bottle (SD; range).

\section{Treatment cost estimation}

Treatment costs, expressed as euros (2008), were estimated for each country and agent in terms of average drop count and local retail price. Annual and daily costs were calculated for each agent and country, based on local public prices ${ }^{26-29}$ and treatment durations of 28 and 31 days per month, as specified in the Summary of Product Characteristics of the country concerned.

\section{Statistical analysis}

The statistical analysis was performed with SAS software (SAS Institute, North Carolina, USA) Release No. 9.1. All statistical tests were interpreted two-sided with alpha fixed at $5 \%$. 
Drop-sizes (mg) for the first 62 drops per bottle of each agent were analyzed in order to evaluate experimental reliability, and drop-size variability was estimated across instillation days and between countries for each agent.

A nested analysis of variance was conducted separately for each agent comprising 'day' and 'country' factors treated as fixed effects, their possible interaction, and a 'sample factor' nested within the 'country factor'. Except for 1 missing sample (Finland: travoprost $0.004 \%$ ) the design was fully balanced. Homoscedasticity and normality of the residues were checked. Graphs plotted the average daily drop-size evolution per agent for individual countries, or overall, according to observed statistical significances. Stepwise regression analyses determined effects and the best-fitting trend generated by linear, quadratic, and cubic models.

\section{Results}

The daily evolution of average drop-sizes over 1 month is shown in Figures 1 to 3 for monotherapy and Figures 4 to 6 for fixed combination agents. Statistically significant differences in drop-size were observed across simulated instillation days with all agents in all 4 countries. In particular, both the LP (Figure 2) and LP/T (Figure 5) curves differ from those of alternative agents by decreases of average drop-size over time. The TP (Figure 3) and TP/T (Figure 6) curves show slight fluctuations about steady average drop-sizes.

Significant differences between countries were observed with BP and BP/T. The BP curve for Denmark indicates a smaller mean drop-size during the first half of the month, compared to all other countries (Figure 1; $P<0.0001$ ). This is reflected in Table 1 where the mean drop-size was less than in all other countries, which were similar. The BP/T curve for Finland indicates smaller mean drop-sizes across the entire experimental period, especially in the first half of the month, compared to its curves in other countries (Figure 4; $P<0.0001$ ). This conforms to the mean drop-size in Table 1. Other BP/T trend differences between countries indicate increasing mean drop-sizes over time (high at the end of the month) for Denmark and Germany, and a slow biphasic trend for Sweden (decreasing at the start of the month, then rising).

Tables 2 to 9 present the mean total fill and drop-counts of all 6 agents (monotherapy and fixed combinations) per country. Drop-counts were highest for $\mathrm{BP} / \mathrm{T}$ and decreased in the sequence LP/T $>\mathrm{TP} / \mathrm{T}$ in all countries. The mean drop-count per bottle varied from 79 to 115 across all agents, but was always least with LP and LP/T. Given the number of drops required for 62 instillations over 31 days, the remaining 'unused' drops per bottle were least for LP and LP/T $(+21 \%$ to $+24 \%)$ in all countries. The percentage of remaining drops was highest for $\mathrm{TP} / \mathrm{T}(+41 \%$ to $+46 \%)$ in all countries, except Finland, and slightly less for BP and $\mathrm{BP} / \mathrm{T}(+39 \%$ to $+42 \%)$.

Annual and daily costs of glaucoma treatment were calculated for each country based on public retail prices (Tables 2 to 9). Annual costs (based on 28/31 days per month)

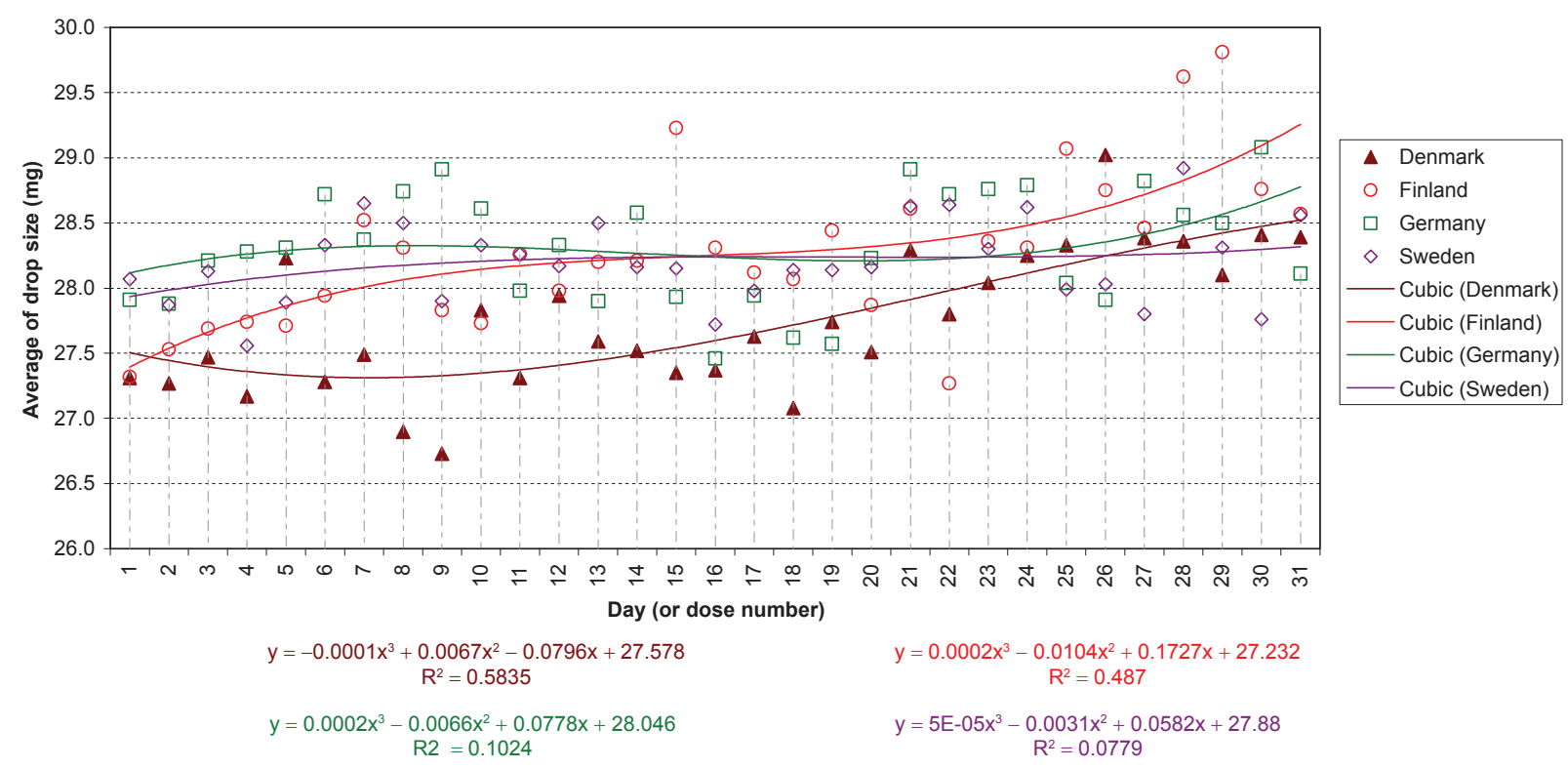

Figure I Bimatoprost $0.03 \%$ : daily average of drop size by country and trend fitting. 


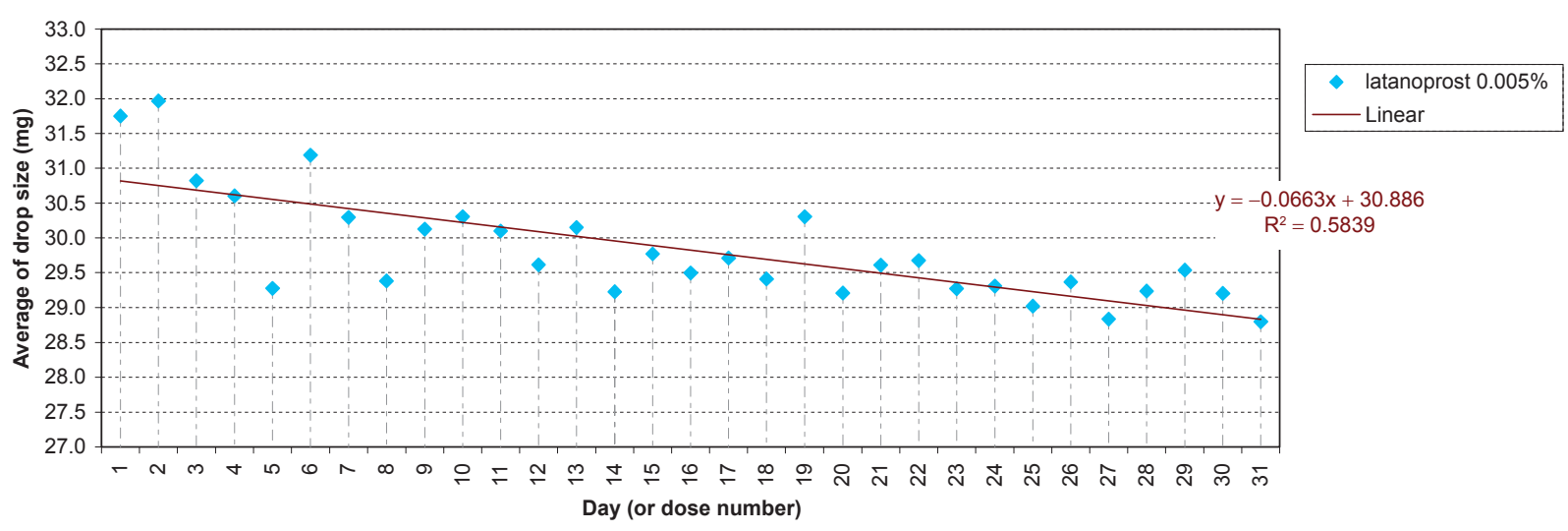

Figure $\mathbf{2}$ Latanoprost $0.005 \%$ : daily average of drop size and trend fitting.

of the three first-line monotherapy agents were higher for LP than BP $(€ 13 / € 12)$ or TP $(€ 22 / € 20)$ in Germany, and higher than BP $(€ 45 / € 40)$ or TP $(€ 45 / € 40)$ in Denmark. In Sweden, TP was cheaper than both BP and LP. For second-line fixed combinations, annual costs were more for LP/T than BP/T (€46/€41) or TP/T (€46/€41) in Sweden. Annual costs were also more for $\mathrm{LP} / \mathrm{T}$ than $\mathrm{BP} / \mathrm{T}(€ 12 / € 10)$ or TP/T (€41/€35) in Germany. In Finland LP/T and BP/T were equal in price, but cost more than TP/T $(€ 12 / € 11)$. In Denmark BP/T cost more than both LP/T (€15/€14) and TP/T (€37/€34), but LP/T cost more than TP/T (€22/€19). Thus, irrespective of country and duration of treatment, the least expensive drug combination overall was TP/T followed by $\mathrm{BP} / \mathrm{T}$ or $\mathrm{LP} / \mathrm{T}$, depending on the country.

\section{Discussion}

Our analysis shows that daily and annual costs of both TP and TP/T, after taking account of product shelf-life, were less than those of all corresponding glaucoma products in all four countries studied.
Our findings differ from those of Frenkel et al who considered that glaucoma products could be used until a bottle is empty. ${ }^{20}$ The latter study was performed in the US, where the healthcare environment and economic analytic methods differed from those of the present study, which followed European Summaries of Product Characteristics recommendations on product shelf-life following bottle opening. Obviously, their estimates would not apply to EU countries in which patients are advised to renew their medication when shelf-life is exceeded.

Lastly, their cost-effectiveness decision rule was based on average ratio, while incremental cost-effectiveness ratio is the estimate which is recommended by most health economics guidelines, leading to inefficient resource allocation. Also, IOP, a surrogate end-point of glaucoma progression, was used as an effectiveness parameter, although it is no more than a clinical trial efficacy parameter. Health authorities are not paying to reduce IOP, but to avoid blindness.

Drop-size has economic significance, too, which may be understood as follows. The conjunctival cul-de-sac normally

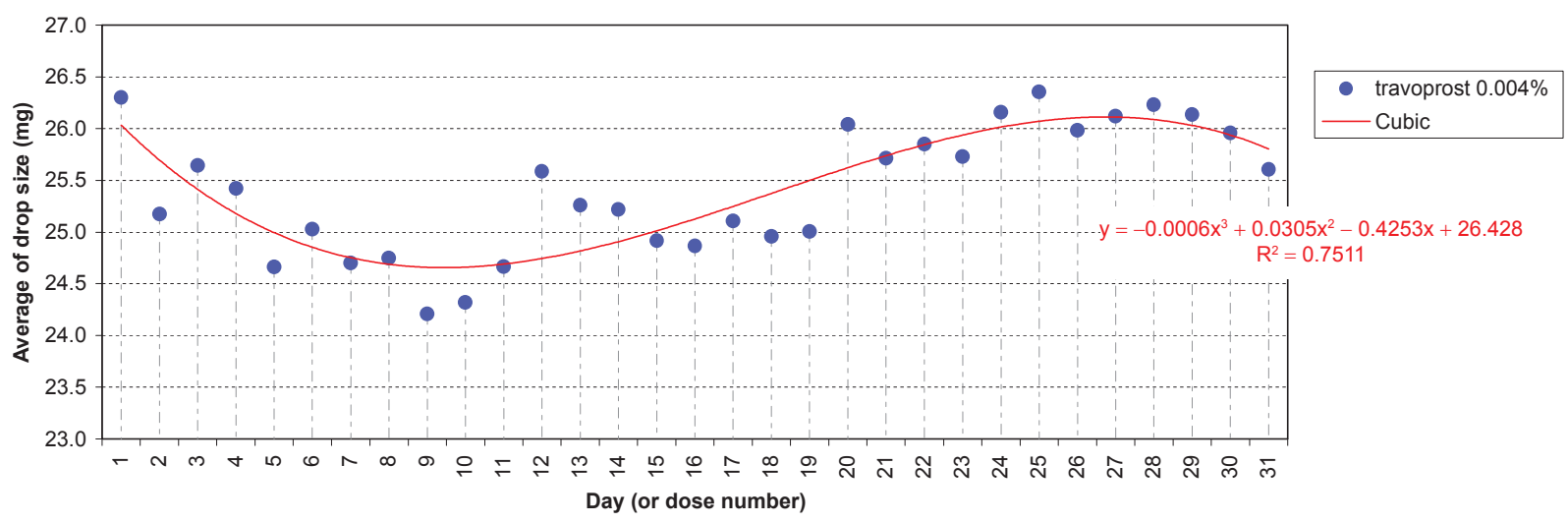

Figure 3 Travoprost $0.004 \%$ : daily average of drop size and trend fitting. 


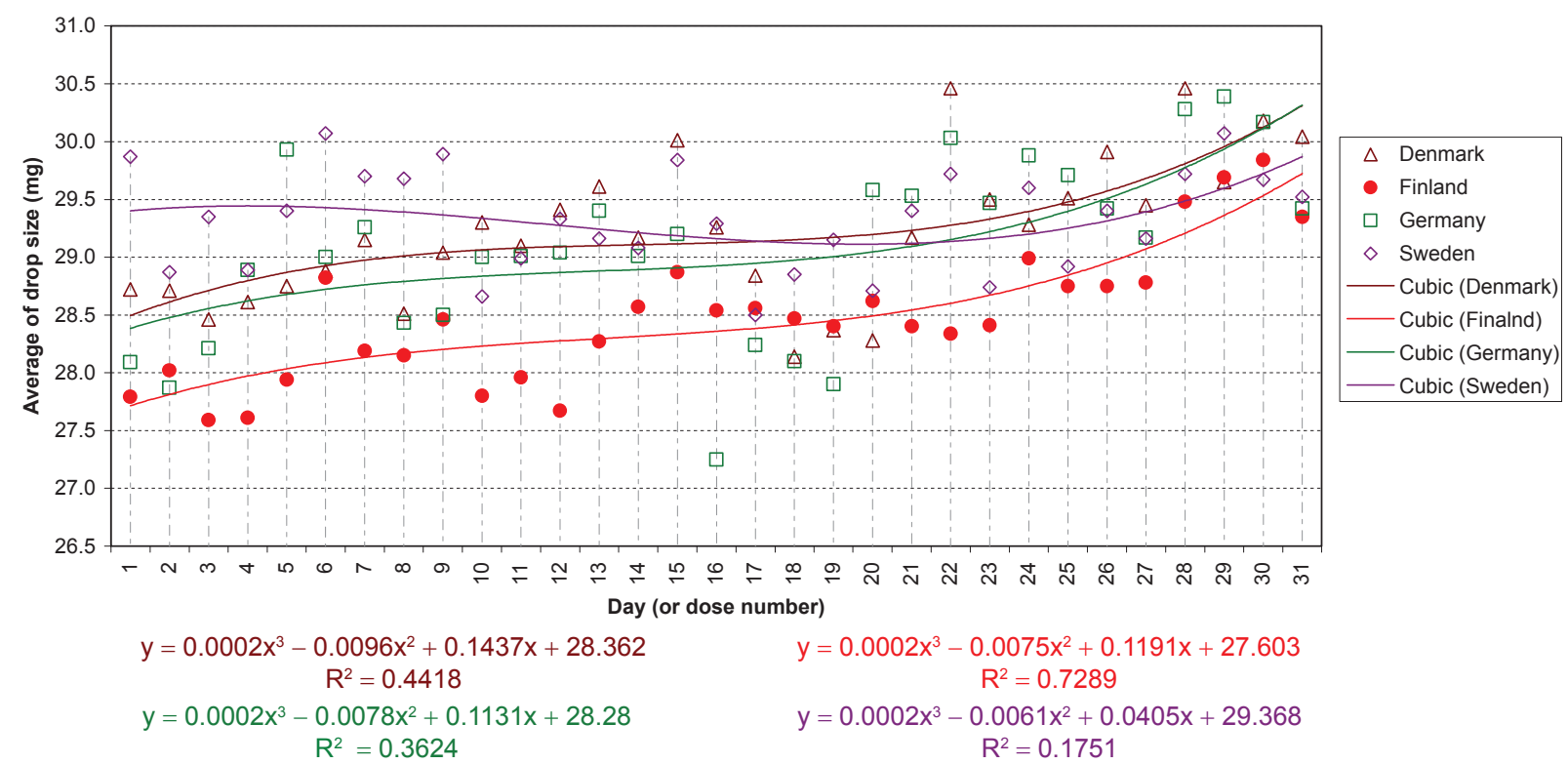

Figure 4 Bimatoprost $0.03 \%$ + timolol: daily average of drop size by country and trend fitting.

holds 7 to $9 \mu \mathrm{L}$ of tears ${ }^{30,31}$ and contains a maximum fluid content of about $30 \mu \mathrm{L} .{ }^{30}$ Hence, an instillation volume of $20 \mu \mathrm{L}$ is usually considered adequate. ${ }^{32}$ In fact, the average drop-size in all countries studied always exceeded $20 \mu \mathrm{L}$, but only the first $20 \mu \mathrm{L}$ would remain in the eye. Some of the remainder would be partially absorbed, with possible systemic effects, with the remainder coursing down the cheek and leading to possible skin effects. Nonetheless, a sufficient delivery of drug into the eye is assured. However, from bioavailability and toxicological points of view volumes $<20 \mu \mathrm{L}$ should be instilled. ${ }^{33-35}$ Moreover, smaller drop-sizes minimize waste and increase the number of drops available from bottles filled to a standard volume. Amongst monotherapy products TP bottles delivered the smallest drop sizes, as did TP/T amongst fixed combinations. Drop-size is determined by various factors, eg, design and physical characteristics of the dropper tip and bottle, physico-chemical properties of the solution, and the manner in which the patient dispenses drops. ${ }^{36}$

The methods we used to count drops were highly standardized in order to minimize the biases when comparing drop counts between brands. Therefore, it probably does not truly reflect the clinical reality of glaucoma patients and counts realized according to daily practice might be associated with higher variability. However, we think that the probability of getting contradictory results in daily practice might be low, when brand bottles look very similar. Drop counts collected with a medical device at the patient home would be required to confirm our findings.

All sampled eye-drop bottles provided sufficient drops for 28 to 31 days of treatment, as required by the Summaries of

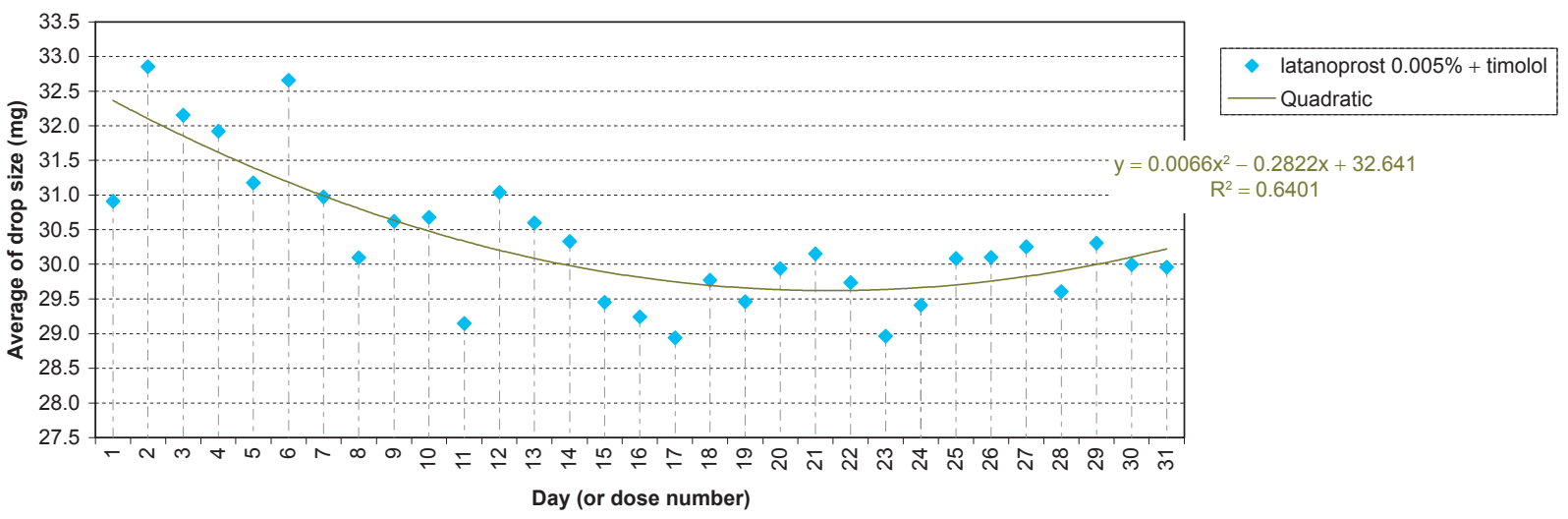

Figure $\mathbf{5}$ Latanoprost $\mathbf{0 . 0 0 5 \%}+$ timolol: daily average of drop size and trend fitting. 


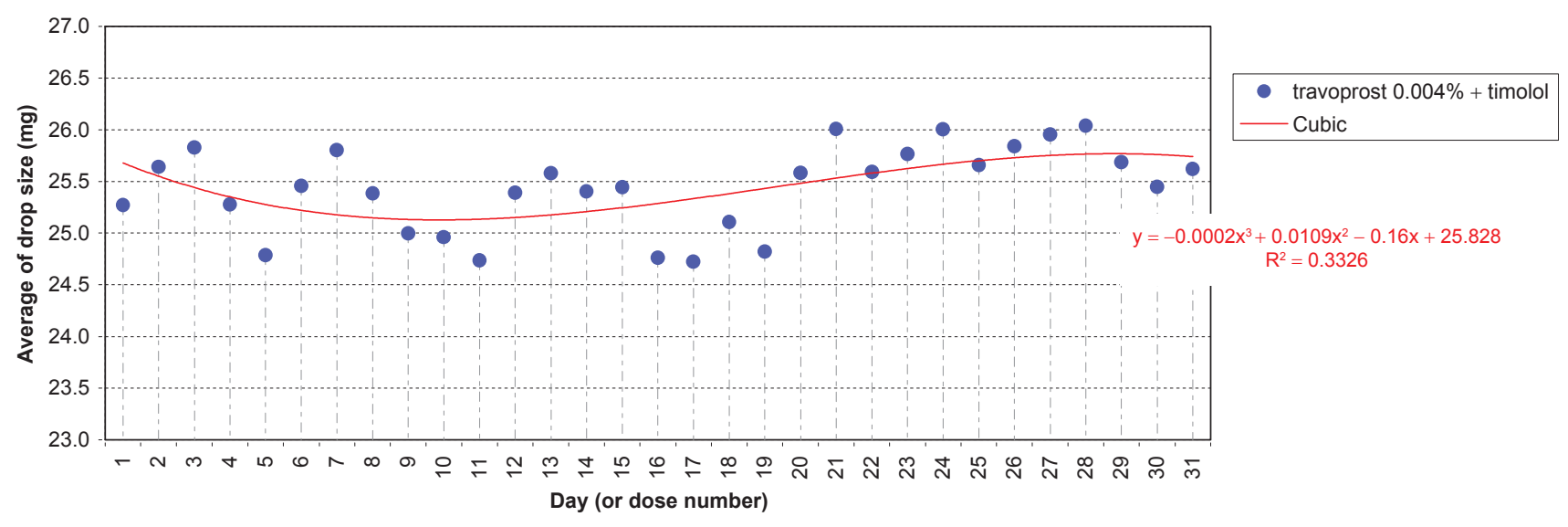

Figure 6 Travoprost $0.004 \%+$ timolol: daily average of drop size and trend fitting.

Product Characteristics. Extra drops were an assurance that the bottles could be used up to at least 28 or 31 days. Among monotherapy products, TP and BP provided greater surety than LP in all 4 countries. For fixed combination products, $\mathrm{TP} / \mathrm{T}$ provided the greatest reserve in all 4 countries. Extra drops are important as older and some younger patients find it difficult to instill glaucoma drops and sometimes may miss entirely. ${ }^{37-39}$ In such situations TP and TP/T bottles provided the greatest reserve of drops, despite containing less fluid than their competitors.

The fact that for $\mathrm{BP}$ and $\mathrm{BP} / \mathrm{T}$ we found different drop-counts between countries raises the question of cost generalizations between countries and suggests that purchasers might well conduct counts before reaching decisions. Also, parallel imports might not be neutral in terms of the number of drops provided.

Table I Daily drop-size $(\mathrm{mg})$ by country of each drug

\begin{tabular}{|c|c|c|c|c|c|c|}
\hline Drug & Drug & Country & $\mathbf{N}$ & Mean & (SD) & [Range] \\
\hline \multirow[t]{12}{*}{ PGA } & bimatoprost $0.03 \%$ & Denmark & 310 & 27.74 & $(0.943)$ & {$[23.1-3 \mid .0]$} \\
\hline & & Finland & 310 & 28.28 & $(1.211)$ & {$[25.9-34.4]$} \\
\hline & & Germany & 310 & 28.31 & $(0.929)$ & {$[25.9-31.2]$} \\
\hline & & Sweden & 310 & 28.20 & $(0.842)$ & {$[23.1-30.8$} \\
\hline & latanoprost $0.005 \%$ & Denmark & 310 & 29.99 & $(3.158)$ & {$[21.9-48.0]$} \\
\hline & & Finland & 310 & 29.75 & $(3.373)$ & {$[20.0-48.9]$} \\
\hline & & Germany & 310 & 29.86 & $(2.93 \mathrm{I})$ & {$[22.9-49.1]$} \\
\hline & & Sweden & 310 & 29.70 & $(3.002)$ & {$[22.5-49.0]$} \\
\hline & travoprost $0.004 \%$ & Denmark & 310 & 25.87 & $(1.415)$ & {$[20.6-32.6]$} \\
\hline & & Finland & 248 & 25.04 & $(1.756)$ & {$[17.6-28.6]$} \\
\hline & & Germany & 310 & 26.06 & $(2.168)$ & {$[15.5-33.9]$} \\
\hline & & Sweden & 310 & 24.58 & $(1.857)$ & {$[19.4-32.1]$} \\
\hline \multirow[t]{12}{*}{ PGA/timolol } & bimatoprost $0.03 \%+$ timolol & Denmark & 310 & 29.22 & $(1.100)$ & {$[25.3-33.2]$} \\
\hline & & Finland & 310 & 28.49 & $(1.017)$ & {$[25.2-31.4]$} \\
\hline & & Germany & 310 & 29.08 & $(1.308)$ & {$[22.9-35.4]$} \\
\hline & & Sweden & 310 & 29.33 & $(0.995)$ & {$[25.3-32.8]$} \\
\hline & latanoprost $0.005 \%+$ timolol & Denmark & 310 & 30.18 & $(2.52)$ & {$[12.6-50.8]$} \\
\hline & & Finland & 310 & 30.54 & $(2.692)$ & {$[20.6-46.1]$} \\
\hline & & Germany & 310 & 30.42 & $(2.803)$ & {$[21.8-46.5$} \\
\hline & & Sweden & 310 & 30.22 & $(3.326)$ & {$[20.2-53.9]$} \\
\hline & & Denmark & 310 & 25.79 & $(1.3 \mid 3)$ & {$[21.8-29.4]$} \\
\hline & travoprost $0.004 \%+$ timolol & Finland & 310 & 25.54 & $(1.567)$ & {$[18.9-28.9]$} \\
\hline & & Germany & 310 & 25.85 & $(1.329)$ & {$[20.6-30.2]$} \\
\hline & & Sweden & 310 & 24.57 & (1.694) & [18.3-28.7] \\
\hline
\end{tabular}

Abbreviations: $\mathrm{N}$, number of weighted drops; PGA, prostaglandin analogue; SD, standard deviation. 
Table 2 Prostaglandin analogue monotherapy bottle contents and costs (euros) for Denmark

\begin{tabular}{llll}
\hline & Bimatoprost 0.03\% (BP) & Latanoprost 0.005\% (LP) & Travoprost 0.004\% (TP) \\
\hline Total fill (g) & $3.22 \pm 0.09$ & $3.01 \pm 0.02$ & $2.63 \pm 0.01$ \\
[Range] & {$[3.09-3.3 I]$} & {$[2.99-3.04]$} & {$[2.63-2.65]$} \\
Number of drops & $104 \pm 2$ & $79 \pm 2$ & $94 \pm 5$ \\
[Range] & {$[102-107]$} & {$[75-80]$} & {$[90-101]$} \\
No. days treatment per month & $31 / 28$ & $31 / 28$ & $31 / 28$ \\
\% drops remaining after & $41 \% / 46 \%$ & $21 \% / 29 \%$ & $34 \% / 41 \%$ \\
monthly treatment (3I/28 days) & & & 20.94 \\
Product public price & 20.95 & 24.36 & 247 \\
Annual cost (3I days) & 247 & 287 & 0.675 \\
Daily cost (3I days) & 0.676 & 0.786 & 273 \\
Annual cost (28 days) & 273 & 318 & 0.748 \\
Daily cost (28 days) & 0.748 & 0.870 & \\
\hline
\end{tabular}

Of course, pharmaceutical savings are not sufficient when considering treatment costs and must be set in the context of effectiveness. In this respect, a recent meta-analysis by Denis et $\mathrm{l}^{19}$ showed that monotherapy with 2 recent PGAs (TP and BP) were more effective than LP in controlling IOP. According to data in the UK GPRD, the probability of no treatment switch with TP as first-line treatment was $69.5 \%$ after 1 year. ${ }^{40}$ On applying the IRR (1.17), measured by Denis et al ${ }^{19}$ the probability of no treatment switches with LP as first-line treatment was $59.4 \%$, about $10 \%$ more than with TP. Therefore, costs generated by more frequent treatment switches ${ }^{41}$ must be added to the higher price of LP. Consequently, in the present 4 European countries, TP would better control IOP at a lower treatment cost.

A similar conclusion may be drawn for second-line fixed combination treatments. According to Denis et $\mathrm{al}^{42}$ the probability of a treatment switch with TP/T instillations is less than for $\mathrm{LP} / \mathrm{T}$. Consequently, patients treated with the first-line/second-line sequence TP/TP/T would experience fewer treatment failures than those treated with the LP/LP/T sequence. At 60 months TP used as the first-line prostaglandin followed by TP/T as the second-line treatment would avoid one third-line prescription in every 11 incident cases. Since, in the present 4 countries, TP and TP/T drug costs were less than those of LP and LP/T, respectively, the former drug sequence would provide a better IOP control at a lower treatment cost. A full costeffectiveness analysis needs to be conducted to confirm these hypotheses.

Our survey suffers from several limitations. First, we purchased only a maximum of 5 bottles in each country from a single selected pharmacy, hence national extrapolation is questionable. Second, we assumed that our procedure mimicked the patients' mode of instillation. Our standardized

Table 3 Prostaglandin analogue monotherapy bottle contents and costs (euros) for Finland

\begin{tabular}{llll}
\hline & Bimatoprost 0.03\% (BP) & Latanoprost 0.005\% (LP) & Travoprost 0.004\% (TP) \\
\hline Total fill (g) & $3.31 \pm 0.08$ & $3.00 \pm 0.02$ & $2.74 \pm 0.01$ \\
[Range] & {$[3.249-3.43]$} & {$[2.97-3.02]$} & {$[2.73-2.74]$} \\
Number of drops & $103 \pm 4$ & $79 \pm 3$ & $104 \pm 11$ \\
[Range] & {$[98-109]$} & {$[74-82]$} & {$[93-116]$} \\
No. days treatment per month & $31 / 28$ & $31 / 28$ & $31 / 28$ \\
\% drops remaining after monthly & $40 \% / 45 \%$ & $21 \% / 29 \%$ & $41 \% / 46 \%$ \\
treatment (3I/28 days) & & & 24.11 \\
Product public price & 24.97 & 24.97 & 284 \\
Annual cost (3I days) & 294 & 294 & 0.778 \\
Daily cost (3I days) & 0.805 & 0.805 & 314 \\
Annual cost (28 days) & 326 & 326 & 0.861 \\
Daily cost (28 days) & 0.892 & 0.892 & \\
\hline
\end{tabular}


Table 4 Prostaglandin analogue monotherapy bottle contents and costs (euros) for Germany

\begin{tabular}{llll}
\hline & Bimatoprost 0.03\% (BP) & Latanoprost 0.005\% (LP) & Travoprost 0.004\% (TP) \\
\hline Total fill (g) & $3.22 \pm 0.09$ & $3.01 \pm 0.02$ & $2.68 \pm 0.01$ \\
[Range] & {$[3.09-3.3 I]$} & {$[2.99-3.04]$} & {$[2.66-2.69]$} \\
Drop-count & $103 \pm 3$ & $79 \pm 4$ & $92 \pm 4$ \\
[Range] & {$[98-106]$} & {$[73-82]$} & {$[89-99]$} \\
No. days treatment per month & $31 / 28$ & $31 / 28$ & $31 / 28$ \\
\% drops remaining after monthly & $40 \% / 45 \%$ & $22 \% / 29 \%$ & $33 \% / 39 \%$ \\
treatment (3I/28 days) & & & 29.88 \\
Product public price & 30.61 & 31.61 & 352 \\
Annual cost (3I days) & 360 & 372 & 0.964 \\
Daily cost (3I days) & 0.987 & 1.020 & 390 \\
Annual cost (28 days) & 399 & 412 & 1.067 \\
Daily cost (28 days) & 1.093 & 1.129 & \\
\hline
\end{tabular}

Table 5 Prostaglandin analogue monotherapy bottle contents and costs (euros) for Sweden

\begin{tabular}{llll}
\hline & Bimatoprost 0.03\% (BP) & Latanoprost 0.005\% (LP) & Travoprost 0.004\% (TP) \\
\hline Total fill (g) & $3.22 \pm 0.05$ & $3.00 \pm 0.03$ & $2.82 \pm 0.15$ \\
[Range] & {$[3.18-3.28]$} & {$[2.96-3.03]$} & {$[2.71-2.99]$} \\
Number of drops & $103 \pm 2$ & $79 \pm 2$ & $115 \pm 10$ \\
[Range] & {$[100-105]$} & {$[77-81]$} & {$[102-128]$} \\
No. days treatment per month & $31 / 28$ & $31 / 28$ & $31 / 28$ \\
\% drops remaining after monthly & $40 \% / 45 \%$ & $21 \% / 29 \%$ & $46 \% / 51 \%$ \\
treatment (3I/28 days) & & & 20.93 \\
Product public price & 21.77 & 21.77 & 246 \\
Annual cost (3I days) & 256 & 256 & 0.675 \\
Daily cost (3I days) & 0.702 & 0.702 & 273 \\
Annual cost (28 days) & 284 & 284 & 0.748 \\
Daily cost (28 days) & 0.778 & 0.778 & \\
\hline
\end{tabular}

Table 6 Prostaglandin analogue/timolol fixed combination bottle contents and costs (euros) for Denmark

\begin{tabular}{llll}
\hline & Bimatoprost 0.03\%/timolol BP/T & Latanoprost 0.005\%/timolol LP/T & Travoprost 0.004\%/timolol TP/T \\
\hline Total fill (g) & $3.28 \pm 0.09$ & $3.03 \pm 0.05$ & $2.87 \pm 0.01$ \\
[Range] & {$[3.20-3.4 I]$} & {$[2.98-3.07]$} & {$[2.86-2.88]$} \\
Number of drops & $102 \pm 3$ & $82 \pm 1$ & $104 \pm 5$ \\
{$[$ Range] } & {$[99-106]$} & {$[8 I-83]$} & {$[99-1 / 2]$} \\
No. days treatment per month & $31 / 28$ & $31 / 28$ & $31 / 28$ \\
\% drops remaining after & $39 \% / 45 \%$ & $24 \% / 32 \%$ & $41 \% / 46 \%$ \\
monthly treatment (3I/28 days) & & & 27.64 \\
Product public price & 30.46 & 29.29 & 325 \\
Annual cost (3I days) & 359 & 345 & 0.892 \\
Daily cost (3I days) & 0.982 & 0.945 & 360 \\
Annual cost (28 days) & 397 & 382 & 0.987 \\
Daily cost (28 days) & 1.088 & 1.046 & \\
\hline
\end{tabular}


Table 7 Prostaglandin analogue/timolol fixed combination bottle contents and costs (euros) for Finland

\begin{tabular}{llll}
\hline & Bimatoprost 0.03\%/timolol BP/T & Latanoprost 0.005\%/timolol LP/T & Travoprost 0.004\%/timololTP/T \\
\hline Total fill (g) & $3.36 \pm 0.04$ & $3.01 \pm 0.01$ & $2.83 \pm 0.01$ \\
[Range] & {$[3.32-3.42]$} & {$[3.00-3.03]$} & {$[2.82-2.84]$} \\
Number of drops & $107 \pm 2$ & $79 \pm 1$ & $107 \pm 10$ \\
{$[$ Range $]$} & {$[104-110]$} & {$[78-80]$} & {$[97-124]$} \\
No. days treatment per month & $31 / 28$ & $31 / 28$ & $31 / 28$ \\
$\%$ drops remaining after monthly & $42 \% / 47 \%$ & $22 \% / 29 \%$ & $42 \% / 47 \%$ \\
treatment (3I/28 days) & & & 29.85 \\
Product public price & 30.73 & 30.73 & 351 \\
Annual cost (3I days) & 362 & 362 & 0.963 \\
Daily cost (3I days) & 0.991 & 0.991 & 389 \\
Annual cost (28 days) & 401 & 401 & 1.066 \\
Daily cost (28 days) & 1.098 & 1.098 & \\
\hline
\end{tabular}

Table 8 Prostaglandin analogue timolol fixed combination bottle contents and costs (euros) for Germany

\begin{tabular}{llll}
\hline & Bimatoprost 0.03\%/timolol BP/T & Latanoprost 0.005\%/timolol LP/T & Travoprost 0.004\%/timolol TP/T \\
\hline Total fill (g) & $3.49 \pm 0.06$ & $3.03 \pm 0.02$ & $2.85 \pm 0.02$ \\
[Range] & {$[3.43-3.58]$} & {$[3.01-3.05]$} & {$[2.82-2.86]$} \\
Number of drops & $105 \pm 3$ & $80 \pm 1$ & $108 \pm 6$ \\
{$[$ Range $]$} & {$[100-108]$} & {$[78-82]$} & {$[100-116]$} \\
No. days treatment per month & $31 / 28$ & $31 / 28$ & $31 / 28$ \\
\% drops remaining after monthly & $41 \% / 47 \%$ & $24 \% / 30 \%$ & $42 \% / 48 \%$ \\
treatment (3I/28 days) & & & 31.17 \\
Product public price & 33.18 & 34.12 & 367 \\
Annual cost (3I days) & 391 & 402 & 1.005 \\
Daily cost (3I days) & 1.070 & 1.101 & 406 \\
Annual cost (28 days) & 433 & 445 & 1.113 \\
Daily cost (28 days) & 1.185 & 1.219 & 4 \\
\hline
\end{tabular}

Table 9 Prostaglandin analogue/timolol fixed combination bottle contents and costs (euros) for Sweden

\begin{tabular}{llll}
\hline & \multicolumn{1}{c}{ Bimatoprost 0.03\%/timolol BP/T } & Latanoprost 0.005\%/timolol LP/T & Travoprost 0.004\%/timolol TP/T \\
\hline Total fill (g) & $3.29 \pm 0.04$ & $3.03 \pm 0.03$ & $2.83 \pm 0.02$ \\
[Range] & {$[3.22-3.34]$} & {$[2.99-3.06]$} & {$[2.81-2.85]$} \\
Number of drops & $102 \pm 3$ & $80 \pm 1$ & $115 \pm 9$ \\
[Range] & {$[98-104]$} & {$[79-81]$} & {$[102-125]$} \\
No. days treatment per month & $31 / 28$ & $31 / 28$ & $31 / 28$ \\
\% drops remaining after monthly & $39 \% / 45 \%$ & $23 \% / 30 \%$ & $46 \% / 51 \%$ \\
treatment (3I/28 days) & & & 25.50 \\
Product public price & 25.50 & 28.96 & 300 \\
Annual cost (3I days) & 300 & 341 & 0.823 \\
Daily cost (3I days) & 0.823 & 0.934 & 332 \\
Annual cost (28 days) & 332 & 378 & 0.911 \\
Daily cost (28 days) & 0.911 & 1.034 & \\
\hline
\end{tabular}


methodology, however, allowed us to obtain unbiased drop-counts from all bottles. Nonetheless, we recognize that real life instillation practices vary widely and that the drop-size ranges we used are probably under-estimated. Third, the evaluation was not 'blinded', ie, the investigator knew the treatment in each bottle. However, our measurements were objective and our procedures standardized, reproducible and validated. Fourth, we used only direct drug costs when claiming for lower cost, other costs were not taken into account. Hence, our survey is preliminary and a full evaluation is under investigation. On the other hand, from a societal point of view, costs are known to increase with accumulating treatment failures. ${ }^{41}$ Hence, the cost differences reported in this paper represent a conservative estimate of the true differences. Fifth, no sensitivity analysis was performed for potential wasted drops, ie, missed instillations and monthly extra drops used in real life. These associated costs, however, may be extrapolated directly from the tables. Lastly, we did not account for patient compliance which is known to be rather poor in glaucoma treatment. ${ }^{43,44}$ This could affect the number of days within a bottle, especially if patients do not account for the expiratory date.

\section{Conclusions}

In Denmark, Finland, Germany and Sweden, eye-drop bottles of travoprost $0.004 \% \pm$ timolol incurred the lowest annual treatment costs, while providing sufficient surplus to compensate for potential fluid wastage from missed instillations, when compared to bimatoprost $0.03 \% \pm$ timolol and latanoprost $0.005 \% \pm$ timolol.

\section{Disclosures and acknowledgments}

This study was supported by an unrestricted grant from Alcon France SA, Rueil-Malmaison, France, and was conducted according to local laws. It was contracted to IMS France, Puteaux, France. Gilles Berdeaux is employed by Alcon France.

We would like to thank Robert Pigache MD for reviewing the English language.

\section{References}

1. Maier PC, Funk J, Schwartzer G, Anter G, Falck-Ytter YT. Treatment of ocular hypertension and open angle glaucoma: meta-analysis of randomised controlled trials. BMJ. 2005;331:134.

2. The AGIS Investigators. The Advanced Glaucoma Intervention Study (AGIS): 7. The relationship between control of intraocular pressure and visual field deterioration. Am J Ophthalmol. 2000;130: 429-440.

3. Cheng JW, Wei RL. Meta-analysis of 13 randomized controlled trials comparing bimatoprost with latanoprost in patients with elevated intraocular pressure. Clin Ther. 2008;30:622-632.
4. Denis P, Launois R, Devaux M, Berdeaux G. Comparison of diurnal intraocular pressure control by latanoprost versus travoprost: results of an observational survey. Clin Drug Investig. 2006;26:703-714.

5. Dirks MS, Noecker RJ, Earl M, Roh S, Williams RD. A 3-month clinical trial comparing the IOP-lowering efficacy of bimatoprost and latanoprost in patients with normal-tension glaucoma. Adv Ther. 2006; 23:385-394.

6. Dubiner HB, Sircy MD, Landry T, et al. Comparison of the diurnal ocular hypotensive efficacy of travoprost and latanoprost over a 44-hour period in patients with elevated intraocular pressure. Clin Ther. 2004;26:84-91.

7. García-Feijoo J, Martínez-de-la-Casa JM, Castillo A, Méndez C, Fernández-Vidal A, García-Sánchez J. Circadian IOP-lowering efficacy of travoprost $0.004 \%$ ophthalmic solution compared to latanoprost 0.005\%. Curr Med Res Opin. 2006;22:1689-1697.

8. Hepsen IF, Ozkaya E. 24-h IOP control with latanoprost, travoprost, and bimatoprost in subjects with exfoliation syndrome and ocular hypertension. Eye. 2007;21:453-458.

9. Konstas AG, Holló G, Irkec M, et al. Diurnal IOP control with bimatoprost versus latanoprost in exfoliative glaucoma: a crossover, observermasked, three-centre study. Br J Ophthalmol. 2007;91:757-760.

10. Konstas AG, Kozobolis VP, Katsimpris IE, et al. Efficacy and safety of latanoprost versus travoprost in exfoliative glaucoma patients. Ophthalmol. 2007;114:653-657.

11. Koz OG, Ozsoy A, Yarangumeli A, Kose SK, Kural G. Comparison of the effects of travoprost, latanoprost and bimatoprost on ocular circulation: a 6-month clinical trial. Acta Ophthalmol Scand. 2007;85:838-843.

12. Martinez A, Sanchez M. Bimatoprost/timolol fixed combination vs latanoprost/timolol fixed combination in open-angle glaucoma patients. Eye. 2009;23:810-818.

13. Netland PA, Landry T, Sullivan EK, et al. Travoprost compared with latanoprost and timolol in patients with open-angle glaucoma or ocular hypertension. Am J Ophthalmol. 2001;132:472-484.

14. Noecker RS, Dirks MS, Choplin NT, et al. A six-month randomized clinical trial comparing the intraocular pressure-lowering efficacy of bimatoprost and latanoprost in patients with ocular hypertension or glaucoma. Am J Ophthalmol. 2003;135:55-63.

15. Orzalesi N, Rossetti L, Bottoli A, Fogagnolo P. Comparison of the effects of latanoprost, travoprost, and bimatoprost on circadian intraocular pressure in patients with glaucoma or ocular hypertension. Ophthalmol. 2006;113:239-246.

16. Parrish RK, Palmberg P, Sheu WP, XLT Study Group. A comparison of latanoprost, bimatoprost, and travoprost in patients with elevated intraocular pressure: a 12 -week, randomized, masked-evaluator multicenter study. Am J Ophthalmol. 2003;135:688-703.

17. Quaranta L, Pizzolante T, Riva I, Haidich AB, Konstas AG, Stewart WC. Twenty-four-hour intraocular pressure and blood pressure levels with bimatoprost versus latanoprost in patients with normal-tension glaucoma. Br J Ophthalmol. 2008;92:1227-1231.

18. Topouzis F, Melamed S, Danesh-Meyer H, et al. A 1-year study to compare the efficacy and safety of once-daily travoprost $0.004 \% /$ timolol $0.5 \%$ to once-daily latanoprost $0.005 \% /$ timolol $0.5 \%$ in patients with open-angle glaucoma or ocular hypertension. Eur J Ophthalmol. 2007;17:183-190.

19. Denis P, Lafuma A, Khoshnood B, Mimaud V, Berdeaux G. A metaanalysis of topical prostaglandin analogues intra-ocular pressure lowering in glaucoma therapy. Curr Med Res Opin. 2007;23:601-608.

20. Frenkel REP, Frenkel M, Toler A. Pharmacoeconomic analysis of prostaglandin and prostamide therapy for patients with glaucoma or ocular hypertension. BMC Ophthalmol. 2007;7:16.

21. Gao Y, Wu L, Li A. Daily cost of glaucoma medications in China. J Glaucoma. 2007;16:594-597.

22. Fiscella RG, Green A, Patuszynski DH, Wilensky J. Medical therapy cost considerations for glaucoma. Am J Ophthalmol. 2003;136:18-25.

23. Rylander NR, Vold SD. Cost analysis of glaucoma medications. Am J Ophthalmol. 2008;145:106-113.

24. Azuara-Blanco A, Burr J. The rising cost of glaucoma drugs. $\mathrm{Br} J$ Ophthalmol. 2006;90:130-131. 
25. Vidal. Edition du Vidal. Paris; 2008.

26. Rote List. http://www.rote-liste.de.

27. Social Insurance Institution. Kela. Medicinal products database. http:// asiakas.kela.fi/laakekys_app/LaakekysApplication?kieli=en.

28. TLV. Tandvårds- och läkemedelsförmånsverket. http://www.tlv.se/ in-english/price-database/.

29. Laegemiddel Styrelsen. Danish Medicines Agency. Medicinpriser.dk. http://www.medicinpriser.dk/.

30. Mishima S, Gasset A, Klyce SD, Baum JL. Determination of tear volume and tear flow. Invest Ophthalmol. 1966;5:264-276.

31. Ehlers N. The precorneal film. Biomicroscopical and chemical investigations. Acta Ophthalmol. 1965;Suppl 81:1-134.

32. Mishima S. Clinical pharmacokinetics of the eye. Proctor lecture. Invest Ophthalmol Vis Sci. 1981;21:504-541.

33. Chrai S, Makoid M, Eriksen S, Robinson J. Drop size and initial dosing frequency problems of topically applied ophthalmic drugs. J Pharm Sci. 1974;63:333-338.

34. Shell J. Ophthalmic drug delivery systems. Surv Ophthalmol. 1984;29:1779-1828

35. Urtti A, Salminen L. Minimizing systemic absorption of topically administered ophthalmic drugs. Surv Ophthalmol. 1993;37:435-456.

36. Van Santvliet L, Ludwig A. Determinants of eye drop size. Surv Ophthalmol. 2004;49:197-213.

37. Tsai T, Robin AL, Smith JP 3rd. An evaluation of how glaucoma patients use topical medications: a pilot study. Trans Am Ophthalmol Soc. 2007;105:29-33; Discussion 33-35.
38. Robin AL, Novack GD, Covert DW, Crockett RS, Marcic TS Adherence in glaucoma: objective measurements of once-daily and adjunctive medication use. Am J Ophthalmol. 2007;144:533-540.

39. Sleath B, Robin AL, Covert D, Byrd JE, Tudor G, Svarstad B. Patient-reported behavior and problems in using glaucoma medications. Ophthalmol. 2006;113:431-436.

40. Lafuma A, Berdeaux G. Costs and effectiveness of travoprost versus a dorzolamide + timolol fixed combination in first-line treatment of glaucoma: analysis conducted on the United Kingdom General Practitioner Research Database. Curr Med Res Opin. 2007;23: 3009-3016.

41. Denis P, Lafuma A, Berdeaux G. Medical predictive factors of glaucoma treatment costs. J Glaucoma. 2004;13:283-290.

42. Denis P, Le Pen C, Umuhire D, Berdeaux G. Treatment carryover impacts on effectiveness of intraocular pressure lowering agents, estimated by a discrete event simulation model. Eur J Ophthalmol. 2008; 18:44-51.

43. Traverso CE, Walt JG, Stern LS, Dolgitser M. Pharmacotherapy compliance in patients with ocular hypertension or primary open-angle glaucoma. J Ocul Pharmacol Ther. 2009;25:77-82.

44. Holló G, Kóthy P, Géczy A, Vargha P. Personality traits, depression, and objectively measured adherence to once-daily prostaglandin analog medication in glaucoma. J Glaucoma. 2009;18:288-292.
Clinical Ophthalmology

\section{Publish your work in this journal}

Clinical Ophthalmology is an international, peer-reviewed journal covering all subspecialties within ophthalmology. Key topics include: Optometry; Visual science; Pharmacology and drug therapy in eye diseases; Basic Sciences; Primary and Secondary eye care; Patient Safety and Quality of Care Improvements. This journal is indexed on

Submit your manuscript here: http://www.dovepress.com/clinical-ophthalmology-journal

\section{Dovepress}

PubMed Central and CAS, and is the official journal of The Society of Clinical Ophthalmology (SCO). The manuscript management system is completely online and includes a very quick and fair peer-review system, which is all easy to use. Visit http://www.dovepress.com/ testimonials.php to read real quotes from published authors. 